\title{
PENILAIAN CACAT LUBANG KAIN BERBASIS LIGHT DEPENDENT RESISTOR PADA MIKROKONTROLER ARDUINO UNO
}

\author{
ASSESSMENT OF FABRIC HOLES BASED ON LIGHT DEPENDENT \\ RESISTOR ON ARDUINO UNO MICROCONTROLLER
}

\author{
Ilham Nugraha ${ }^{1}$, Pudjiati ${ }^{2}$ dan Liana Dwi Fitrianti ${ }^{3 *}$ \\ Dosen Jurusan Produksi Garmen, Politeknik STTT Bandung, Bandung, \\ 40272, Indonesia \\ Mahasiswa Jurusan Produksi Garmen, Politeknik STTT Bandung, Bandung, \\ 40272, Indonesia \\ E-mail: lianadwifitrianti@gmail.com
}

\begin{abstract}
ABSTRAK
Kain merupakan komponen utama dalam pembuatan garmen. Kualitas produk garmen dapat dipengaruhi oleh kualitas kain, oleh sebab itu sebelum melakukan proses produksi garmen perlu dilakukan kegiatan inspeksi kain untuk memeriksa keberadaan cacat pada kain. Pada umumnya inspeksi kain di industri garmen menggunakan sebuah mesin inspeksi yang dioperasikan oleh seorang operator. Misalnya terdapat cacat pada permukaan kain yang terlewat ketika diperiksa. Untuk mengurangi jumlah cacat lubang yang terlewat pada kain, maka dilakukan penelitian mengenai studi pendeteksi cacat kain menggunakan Hardware berupa Arduino Uno dengan sensor cahaya (LDR) yang dilakukan pada mesin inspeksi kain sehingga dapat mendeteksi cacat lubang pada kain. Arduino adalah pengendali mikro single-board yang bersifat open-source, dirancang untuk memudahkan penggunaan elektronik dalam berbagai bidang. Hardware dalam arduino memiliki prosesor Atmel AVR dan menggunakan software dan bahasa sendiri. Sensor cahaya LDR ini merupakan resistor yang memiliki karakteristik peka terhadap cahaya. LDR akan dapat mendeteksi cahaya yang melewati lubang kain pada jarak tertentu. Cahaya yang melewati lubang dideteksi sebagai perubahan intensitas cahaya sehingga cacat lubang pada kain dapat terdeteksi berdasarkan ukurannya.
\end{abstract}

Kata kunci: Cacat Lubang Kain, Light Dependent Resistor, Mikrokontroler, Arduino Uno

\begin{abstract}
Fabric is the main component in garment manufacturing. The quality of garment products can be influenced by the quality of the fabric. Before the garment production process, it is necessary to carry out fabric inspection activities to check defects in the fabric. In general, fabric inspection in the garment industry uses an inspection machine operated by an operator. However, an operator may be able to make a mistake. For example, there are defects on the surface of the fabric that missed to be checked. To reduce the number of hole defects that have been missed, a study was conducted on the detection of fabric defects using hardware in the form of an Arduino Uno with a light sensor (LDR) carried out on a fabric inspection machine to detect defects holes in the fabric. Arduino is a single-board open-source micro controller, designed to facilitate the use of electronics in various fields. Arduino hardware has an Atmel AVR processor and
\end{abstract}


uses its oftware and language. This LDR light sensor is a resistor that has sensitive characteristics to light. The LDR will be able to detect light passing through the fabric hole at a certain distance. Light passing through the hole is detected as a change in light intensity so that the hole defect in the fabric can be detected based on its size.

Keywords: Fabric Holes, Light Dependent Resistor, Microcontroller, Arduino Uno

\section{PENDAHULUAN}

\subsection{Latar Belakang}

Kain merupakan komponen utama dalam pembuatan garmen. Kualitas produk garmen dapat dipengaruhi oleh kualitas kain, maka sebelum melakukan proses produksi garmen perlu dilakukan kegiatan inspeksi kain untuk memeriksa keberadaan cacat pada kain. Kegiatan inspeksi kain dilakukan sebelum proses pemotongan pada kain berfungsi sebagai salah satu kegiatan pengendalian mutu. Inspeksi bertujuan tidak hanya sebagai kontrol kualitas, akan tetapi sedini mungkin menghindari proses produksi terganggu akibat keberadaan cacat pada kain yang sudah dipotong. Apabila banyak terjadi pengembalian komponen garmen ke bagian pemotongan maka industri akan melakukan kerja lembur atau over time. Pada umumnya inspeksi kain di industri garmen menggunakan sebuah mesin inspeksi yang dioperasikan oleh seorang operator. Mesin menggerakkan setiap rol kain sehingga operator dapat memindai keberadaan cacat pada permukaan kain. Mesin inspeksi pada umumnya dilengkapi dengan pencahayaan yang dapat memudahkan operator mendeteksi keberadaan cacat melalui indera penglihatan. Akan tetapi seorang operator dapat melakukan kelalaian dalam bekerja. Misalnya terdapat cacat pada permukaan kain yang terlewat untuk diperiksa.

Beberapa faktor mempengaruhi kesiagaan seorang manusia dalam melakukan pekerjaannya. Salah satu faktor yang cukup berpengaruh adalah kelelahan kerja. Kelelahan kerja adalah perasaan lelah dengan adanya penurunan kesiagaan (Lientje, 2010). Kelelahan menunjukkan kondisi yang berbeda-beda dari setiap individu, tetapi semuanya bermuara pada kehilangan efisiensi dan penurunan kapasitas kerja serta ketahanan tubuh (Tarwaka, 2004). Hal ini bertentangan dengan tuntutan kerja pada proses produksi garmen dimana setiap operator dituntut untuk tetap prima dalam bekerja.

Menurut Supriyono (2001) menyatakan bahwa cacat material kain merupakan cacat yang terjadi sebelum pengolahan kain menjadi produk garmen dapat terjadi dalam pengiriman maupun dalam produksi kain yang akan digunakan sebagai bahan baku. Cacat lubang termasuk golongan cacat kritis karena tidak dapat dilakukan perbaikan. Jika komponen yang terdapat cacat lubang lolos ke bagian proses produksi maka komponen tersebut harus diganti dengan komponen yang baru.

Arduino adalah pengendali mikro single-board yang bersifat opensource, dirancang untuk memudahkan penggunaan elektronik dalam berbagai bidang. Hardware dalam arduino memiliki prosesor Atmel AVR dan menggunakan software dan bahasa sendiri. Hardware dalam Arduino memiliki beberapa jenis, yang mempunyai kelebihan dan kekurangan dalam setiap papannya. Penggunaan jenis Arduino disesuaikan dengan kebutuhan, hal ini yang akan mempengaruhi dari jenis prosessor yang digunakan. Jika semakin kompleks perancangan dan program 
yang dibuat, maka harus sesuai pula jenis controller yang digunakan. Yang membedakan antara Arduino yang satu dengan yang lainnya adalah penambahan fungsi dalam setiap papannya dan jenis mikrokontroler yang digunakan. Dalam penelitian ini, jenis Arduino yang digunakan adalah Arduino Uno.

Sensor LDR menurut Novianty dkk (2012) dapat mengubah besaran cahaya menjadi besaran listrik. Sensor cahaya LDR ini merupakan resistor yang memiliki karakteristik peka terhadap cahaya. Penelitian mengenai studi pendeteksi cacat kain menggunakan perangkat keras berupa Arduino Uno dengan sensor cahaya (LDR) dilakukan pada mesin inspeksi kain dapat mendeteksi cacat lubang. LDR akan dapat mendeteksi cahaya yang melewati lubang pada kain pada jarak tertentu. Cahaya yang melewati lubang dideteksi sebagai perubahan intensitas cahaya.

Berdasarkan latar belakang yang telah diuraikan tersebut maka dilakukan pengamatan dan penelitian mengenai pendeteksi cacat kain menggunakan Arduino Uno serta sensor cahaya (LDR). Permasalahan pada penelitian ini dibatasi untuk studi awal deteksi cacat lubang pada kain menggunakan sensor cahaya (LDR) pada mikrokontroler Arduino Uno terhadap kain. Tujuan penelitian ini adalah untuk mengetahui cara mendeteksi cacat lubang kain menggunakan sensor cahaya (LDR)

dan mengetahui sensitivitas alat uji dalam mendeteksi cacat lubang pada kain berdasarkan ukuran luas penampangnya.

\subsection{Landasan Teori}

Menurut Kotler (1992), kualitas produk merupakan keseluruhan ciri serta sifat barang dan jasa yang berpengaruh pada kemampuan dalam memenuhi kebutuhan dan keinginan yang dinyatakan maupun tersirat. Kualitas adalah faktor utama dalam suatu produk yang menyebabkan produk tersebut bernilai sesuai dengan maksud dan tujuan produk tersebut. Kualitas didasarkan pada pengalaman aktual pelanggan, terhadap produk, yang diukur berdasarkan kehendak konsumen. Makin tinggi tingkat kepuasan (degree of delivery) konsumen, makin tinggi mutu barang atau jasa tersebut.

Hendrodyantopo, Hasyim dan Sutanto (2005) menyatakan pengendalian mutu adalah suatu usaha yang berkesinambungan dari suatu upaya untuk menjaga dan memelihara konsistensi kualitas sekaligus meningkatkan mutu produk. Mutu merupakan kombinasi yang beragam karakteristik dari sifat suatu produk, sehingga produk tersebut dapat memuaskan dan dapat digunakan oleh konsumen. Sedangkan Badri dan Romadhon (2012), pengendalian kualitas adalah suatu aktivitas (manajemen perusahaan) untuk menjaga dan mengarahkan agar kualitas produk (dan jasa) perusahaan dapat dipertahankan sebagaimana yang telah direncanakan. Pengendalian mutu bertujuan membantu menghasilkan produk yang benar pada kesempatan pertama, artinya mencegah terjadinya cacat sedini mungkin.

Hendrodyantopo, Hasyim dan Sutanto (2005) menyatakan bahwa umumnya inspeksi dilakukan sebelum proses pemotongan kain untuk menjamin kualitas pakaian dan meningkatkan efisiensi pembuatan garmen sehingga produk dapat diselesaikan tepat waktu. Inspeksi adalah kegiatan pengendalian mutu yang dilakukan dengan cara pengamatan visual dan pengukuran dimensi kain untuk memeriksa apakah produk telah sesuai dengan standar atau spesifikasi mutu yang ditetapkan. 
Inspeksi dilakukan untuk melihat kesalahan atau tingkat cacat, konstruksi kain, dan shading warna pada kain. Dalam inspeksi kain juga terdapat spesifikasi dan toleransi. Cara yang digunakan dalam inspeksi kain adalah sistem penyaringan atau inspeksi 100\%, bertujuan untuk memeriksa seluruh kain dalam menemukan cacat kain.

Janah (2017) menyatakan bahwa cacat adalah kekurangan yang menyebabkan nilai atau mutunya kurang baik atau kurang sempurna. Menurut Supriyono (2001) menyatakan bahwa cacat material kain merupakan cacat yang terjadi sebelum pengolahan kain menjadi produk garmen. Cacat material dapat terjadi dalam pengiriman maupun dalam produksi kain yang akan digunakan sebagai bahan baku. Fitrihana (2013) mengelompokkan cacat kain seperti pada Tabel 1.1.

Tabel 1.1 Daftar Istilah Cacat pada Kain\

\begin{tabular}{|c|c|c|c|}
\hline No & $\begin{array}{c}\text { Istilah Cacat Kain dalam } \\
\text { Bahasa Indonesia }\end{array}$ & $\begin{array}{c}\text { Istilah Cacat Kain dalam } \\
\text { Bahasa Inggris }\end{array}$ & Kode \\
\hline 1 & Timbul benang pendek & Kink & $\mathrm{KN}$ \\
\hline 2 & Timbul simpul benang & Neps & NP \\
\hline 3 & Simpul besar & Big Knot & BK \\
\hline 4 & Timbul benang & Slub & SL \\
\hline 5 & Timbul benang tebal & Coarse pick & $\mathrm{CP}$ \\
\hline 6 & Timbul benang kecil & Thin pick & TP \\
\hline 7 & Garis melintang selebar kain & Filling bar & FB \\
\hline 8 & Belang selebar kain & Shade bar & CB \\
\hline 9 & Bintik selebar kain & Cockied bar & SB \\
\hline 10 & Kemasukkan bahan lain & Gout & CB \\
\hline 11 & Benang putus & Broken pick & GT \\
\hline 12 & Benangrangkap & Double pick & $\mathrm{BP}$ \\
\hline 13 & Benang meloncat & Mispick & DP \\
\hline 14 & Benang kendur & Slack pick & $\mathrm{BP}$ \\
\hline 15 & Benang tegang & Tight pick & Tpg \\
\hline 16 & Tebal benang & Thick place & Tpl \\
\hline 17 & Tipis Benang & Thin place & Thp \\
\hline 18 & Kain berombak & Float & $\mathrm{Ft}$ \\
\hline 19 & Kosong benang berjajar & Shuttle mark & Sm \\
\hline 20 & Benang asli tertarik ke luar & Pick out mark & Pom \\
\hline 21 & Benang kendur & Loose end & Le \\
\hline 22 & Tercampur benang besar & Coarse end & $\mathrm{Ce}$ \\
\hline 23 & Tercampur benang kecil & Fine end & $\mathrm{Fe}$ \\
\hline 24 & Cacat benang & Uneven yarn & Uy \\
\hline 25 & Tercampur benang lain & Mixed end & $\mathrm{Me}$ \\
\hline 26 & Berbeda warna kea rah serat & Warp streak & Ws \\
\hline
\end{tabular}




\begin{tabular}{|c|l|l|c|}
\hline 27 & Putus benang & Broken end & Be \\
\hline 28 & Kosong benang lusi & End out & Eo \\
\hline 29 & Benang ganda & Double end & De \\
\hline 30 & Lebar kain lebih melebar & Slack end & Se \\
\hline 31 & Lebar kain lebih sempit & Tight end & Sa \\
\hline 32 & Cacat kotor & Dirty staining & Ds \\
\hline
\end{tabular}

Tabel 1.1 (Lanjutan) Daftar istilah Cacat pada Kain

\begin{tabular}{|c|l|l|c|}
\hline No & \multicolumn{1}{|c|}{$\begin{array}{c}\text { Istilah Cacat Kain dalam } \\
\text { Bahasa Indonesia }\end{array}$} & $\begin{array}{c}\text { Istilah Cacat Kain dalam } \\
\text { Bahasa Inggris }\end{array}$ & Kode \\
\hline 33 & Kotor oli & O il staining & Os \\
\hline 34 & Terpotong tepi kain & Cut selvedge & $\mathrm{Cs}$ \\
\hline 35 & Pencelupan tidak merrata & Uneven dyeing & Ud \\
\hline 36 & Lubang kecil & S mall hole & $\mathrm{Sh}$ \\
\hline 37 & Lubang besar & S mash & $\mathrm{Sm}$ \\
\hline 38 & Benang beda warna melintang & Barred & $\mathrm{Br}$ \\
\hline 39 & Warna belang & Shade different & $\mathrm{Sd}$ \\
\hline 40 & Melengkung atau tidak lurus & Bow or Slanting & $\mathrm{BW}$ \\
\hline
\end{tabular}

Menurut Kadir (2013) Arduino Uno adalah salah satu produk yang berlabel Arduino yang sebenarnya adalah suatu papan elektronik yang mengandung mikrokontroler ATMega328 (sebuah keping yang secara fungsional bertindak seperti sebuah komputer). Piranti ini dapat dimanfaatkan untuk mewujudkan rangkaian elektronik dari yang sederhana hingga yang kompleks.

Kode Program Arduino biasa disebut sketch dan dibuat menggunakan bahasa pemrograman $\mathrm{C}$. Program atau sketch yang sudah selesai ditulis di Arduino IDE bisa langsung di lakukan compile dan upload ke Arduino Board.

Secara sederhana, sketch dalam Arduino dikelompokkan menjadi 3 blok:

\section{Header}

Pada bagian ini biasanya ditulis definisidefinisi penting yang akan digunakan selanjutnya dalam program, misalnya penggunaan library dan pendefinisian variable. Kode dalam blok ini dijalankan hanya sekali pada waktu compile.

\section{Setup}

Pada blok ini biasa diisi dengan penentuan apakah suatu pin digunakan sebagai input atau output, menggunakan perintah pinMode. Initialisasi variable juga bisa dilakukan di blok ini. Jika difungsikan sebagai output, Arduino Uno siap mengirimkan arus listrik (maksimum $100 \mathrm{~mA}$ ) kepada beban yang disambungkannya. Jika difungsikan sebagai input, pin tersebut memiliki impedance yang tinggi dan siap menerima arus yang dikirimkan kepadanya.

\section{Loop}

Blok ini akan dieksekusi secara terus menerus. Apabila program sudah sampai akhir blok, maka akan dilanjutkan dengan mengulang eksekusi dari awal blok. Program akan berhenti apabila tombol power Arduino dimatikan. Di sinilah fungsi utama program Arduino kita berada.

Perintah digitalWrite (pinNumber,nilai) akan memerintahkan Arduino untuk menyalakan atau mematikan tegangan 
di pinNumber tergantung nilainya. Jadi perintah di atas digitalW rite(led,HIGH); akan membuat pin nomor 13 (karena di header dideklarasi led $=13$ ) memiliki tegangan $=5 \mathrm{~V}(\mathrm{HIGH})$. Hanya ada dua kemungkinan nilai digitalW rite yaitu $\mathrm{HIGH}$ atau LOW yang sebetulnya adalah nilai integer 1 atau 0 . Jika program diatas sudah dibuat, selanjutnya kita ambil kabel USB yang diikutsertakan pada saat membeli Arduino, pasangkan ke komputer dan board Arduino, dan upload programnya. Lampu LED yg ada di Arduino board akan berkelap-kelip. Selain blok setup() dan loop() di atas kita bisa mendefinisikan sendiri blok fungsi sesuai kebutuhan.

Sensor LDR merupakan salah satu komponen listrik yang peka terhadap cahaya, piranti ini bisa disebut juga sebagai fotosel, fotokonduktif atau fotoresistor. LDR memanfaatkan bahan semikonduktor yang karakteristik listriknya berubah-ubah sesuai dengan cahaya yang diterima (Angga dkk, 2016). Jika cahaya yang mengenai bahan semikonduktor pada LDR memiliki frekuensi yang cukup tinggi, foton yang diserap oleh semikonduktor akan menyebabkan elektron memiliki energi yang cukup untuk meloncat ke pita konduksi. Elektron bebas yang dihasilkan (dan pasangan lubangnya) akan mengalirkan listrik, sehingga menurunkan resistansinya (Albet, 2014).

Bahan yang digunakan pada LDR antara lain Kadmium Sulfida (CdS) dan Cadmium Selenida (CdSe). Bahanbahan ini paling sensitif terhadap cahaya dalam spektrum tampak, dengan puncaknya sekitar 0,6 m untuk CdS dan 0,75 m untuk CdSe. Sebuah LDR CdS yang tipikal akan memiliki resistansi sekitar $1 \mathrm{M}$ dalam kondisi gelap gulita dan kurang dari 1 $\mathrm{K}$ ketika ditempatkan di bawah sumber cahaya terang. Dengan kata lain, resistansi LDR sangat tinggi dalam intensitas cahaya yang gelap, sebaliknya resistansi LDR sangat rendah dalam intensitas cahaya yang terang (Angga dkk, 2016).

Karakteristik LDR menurut Albet (2014) terdiri dari dua macam yaitu laju recovery dan respon spektral.

1. Laju Recovery merupakan suatu ukuran praktis dan suatu kenaikan nilai resistansi dalam waktu tertentu. Harga ini ditulis dalam K/detik, untuk LDR tipe arus harganya lebih besar dari 200 $\mathrm{K} /$ detik (selama 20 menit pertama mulai dari level cahaya 100 lux), kecepatan tersebut akan lebih tinggi pada arah sebaliknya, yaitu pindah dari tempat gelap ke tempat terang yang memerlukan waktu kurang dari 10 ms untuk mencapai resistansi yang sesuai dengan level cahaya 400 lux.

2. Respon Spektral berarti LDR tidak mempunyai sensitivitas yang sama untuk setiap panjang gelombang cahaya yang jatuh padanya (warna). Bahan yang biasa digunakan sebagai penghantar arus listrik yaitu tembaga, alumunium, baja, emas dan perak. Dari kelima bahan tersebut tembaga merupakan penghantar yang paling banyak digunakan karena mempunyai daya hantar yang baik.

\section{BAHAN DAN METODA}

Dalam perancangan dan pembuatan suatu perangkat lunak elektronik (software) perlu diperhatikan kualitas bahan yang digunakan dan tingkat keakuratan saat komponen bekerja, serta bentuk dimensi komponen. Alat dan bahan yang digunakan untuk eksperimen ini adalah, Arduino Uno, Sensor LDR, Breadboard, Kabel jumper, Resistor $10 \mathrm{k}$, Resistor 220 , Lampu LED, Laptop ASUS A44s dan kain dengan cacat lubang. Gambar alat 
eksperimen dapat dilihat pada gambar 2.1.

- Arduino Uno, berfungsi sebagai otak yang dapat mengirimkan perintah kepada sensor LDR dalam penelitian ini.

- Breadboard, papan project yang berfungsi sebagai tempat merangkai prototype.
- Kabel jumper, berfungsi sebagai penyambung arus antara komponen satu dengan yang lainnya.

- Resistor, sebagai pembatas arus yang mengalir pada rangkaian.

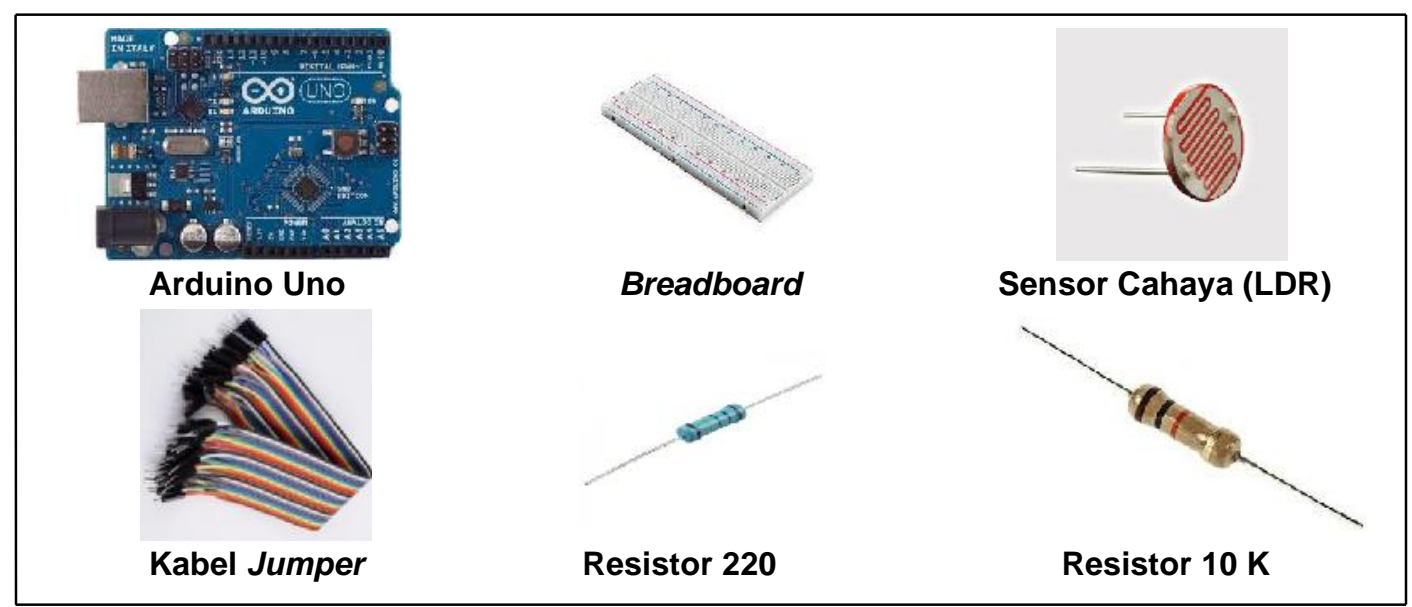

Gambar 2.1 Alat Penelitian

\subsection{Skema Percobaan}

Skema percobaan berupa gambar dapat dilihat pada Gambar 2.2.

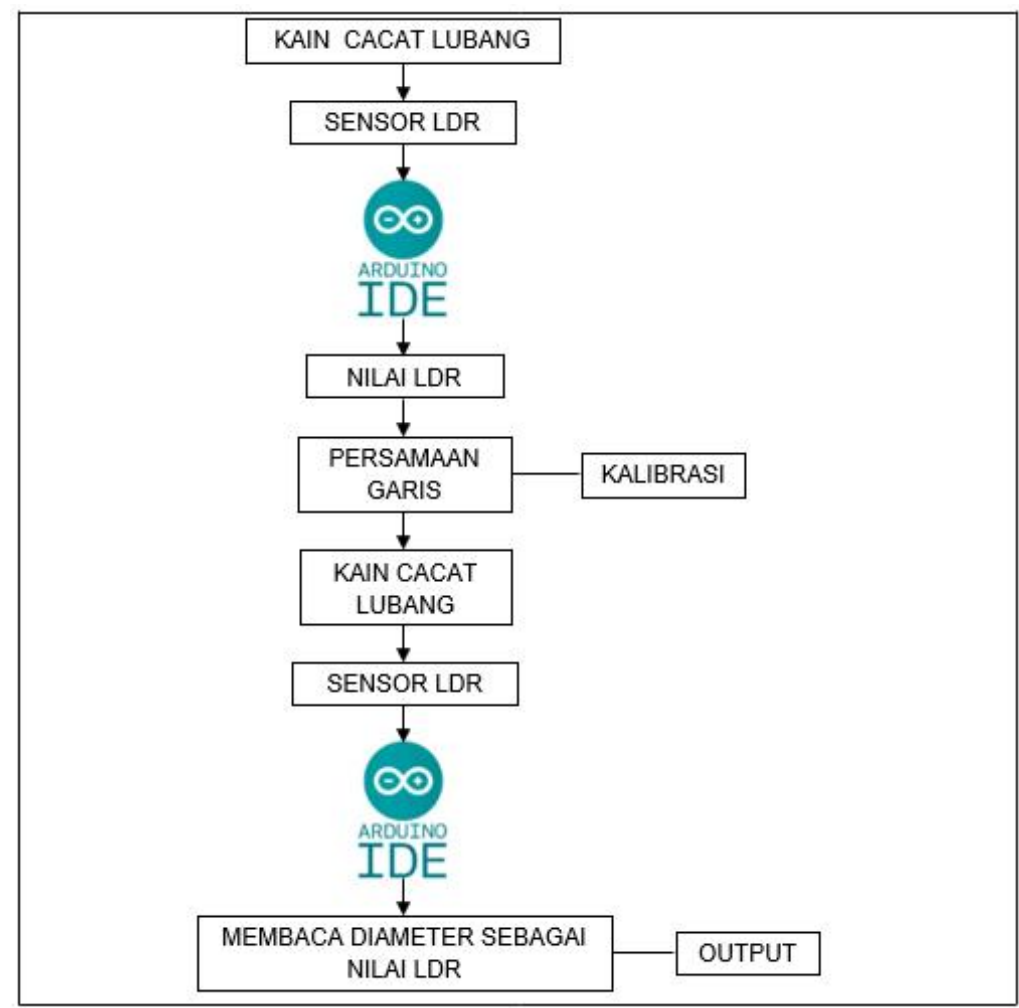




\section{Gambar 2.2 Skema Percobaan}

\subsection{Cara Kerja}

Berikut ini merupakan langkah-langkah yang dilakukan dalam pelaksanaan penelitian:

1. Membuat rangkaian Arduino Uno dan sensor LDR pada breadboard

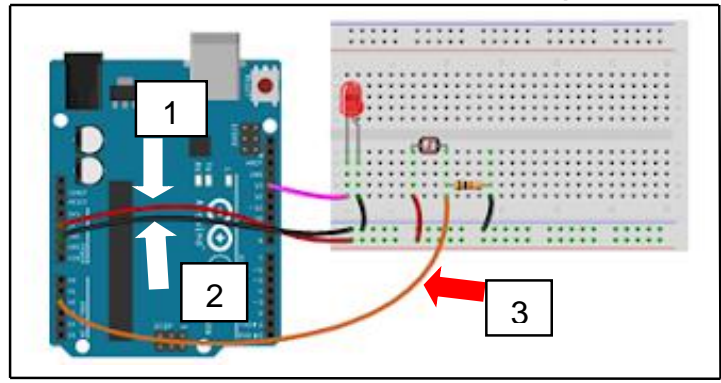

Gambar 2.3 Rangkaian Arduino Uno dan Sensor LDR pada Breadboard

- Kabel 1 sambungkan ke pin arus 5V.

- Kabel 2 pada pin GnD (ground)

- Kabel 3 sambungkan pada pin A2 (analog)

2. Membuat sketch pada software arduino IDE

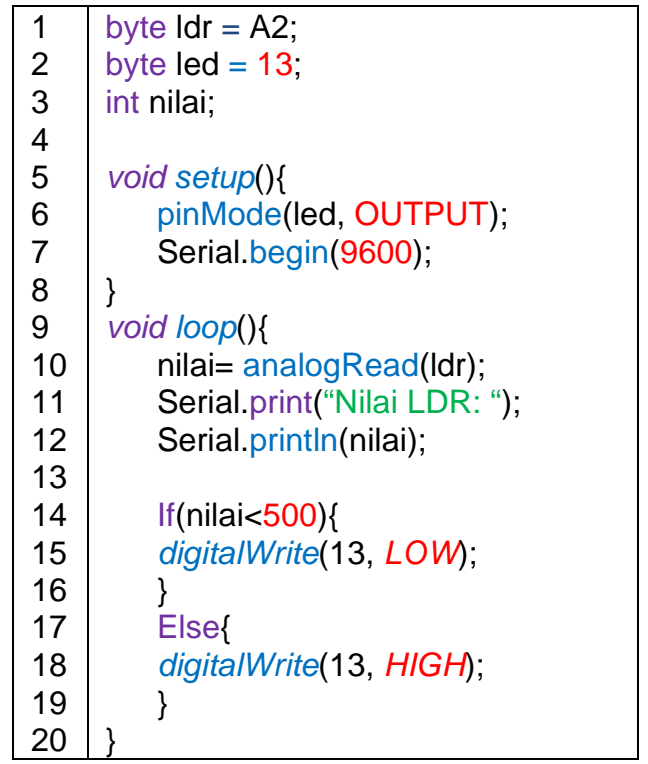

\section{Gambar 2.4 Konfigurasi Kode/S ketch pada Arduino IDE}

- pinMode (led, OUTPUT); memilih mode OUTPUT untuk pin yang disimpan di variabel LED.

- Serial.begin(9600); digunakan agar arduino bisa berkomunikasi dengan komputer.
- nilai $=$ analogRead (LDR); menyimpan nilai yang dibaca oleh sensor LDR ke dalam variabel nilai LDR.

- Serial.print("Nilai LDR: “); digunakan untuk mencetak secara digital atau teks nilai LDR 
untuk ditampilkan pada Serial Monitor.

- Serial.println(nilai); untuk menampilkan nilai yang dibaca oleh sensor LDR.
- If(nilai<500) jika sensor membaca nilai kurang dari 500.

- digitaIW rite(13,LOW); lampu LED pada pin 13 akan mati.

- digitaIWrite(13,HIG H); lampu LED pada pin 13 akan menyala.

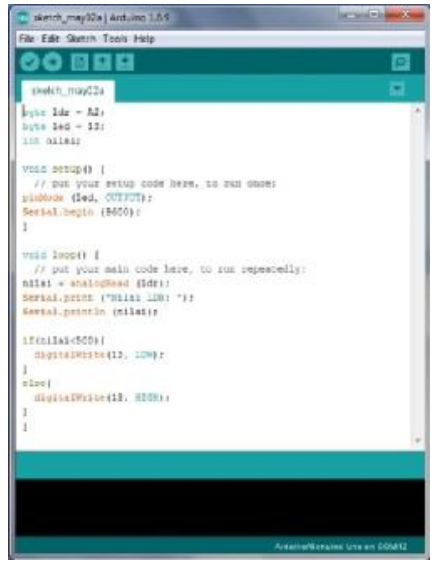

Gambar 2.5 Sketch Arduino IDE

3. Setelah sketch sudah siap, lakukan verifikasi dengan menggunakan tools verify.

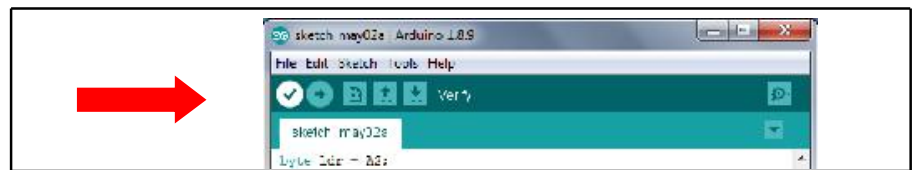

Gambar 2.6 Tools : Verify

4. Jika terdapat kesalahan pada konfigurasi, Arduino IDE akan otomatis mendeteksinya.

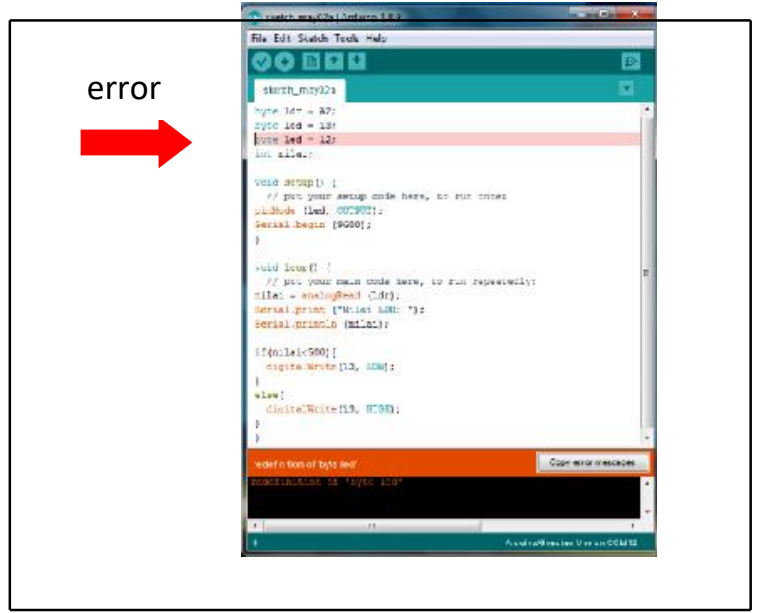

Gambar 2.7 Error pada konfigurasi kode Arduino IDE

5. Meletakkan kain dengan cacat lubang pada mesin inspeksi kain.
Cacat lubang telah diketahui luasnya. 
6. Pengambilan gambar kain dengan cacat lubang beserta alat pengkalibrasi menggunakan webcam.
7. Pada software Arduino IDE, buka serial monitor seperti pada Gambar 2.8

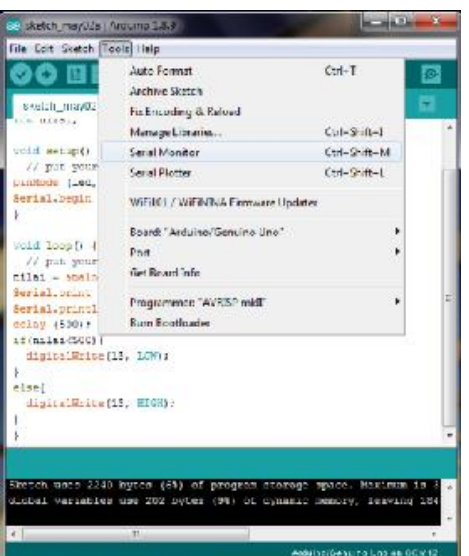

\section{Gambar 2.8 Membuka Serial Monitor}

8. Pada serial monitor akan ditampilkan nilai LDR yaitu besaran intensitas cahaya.

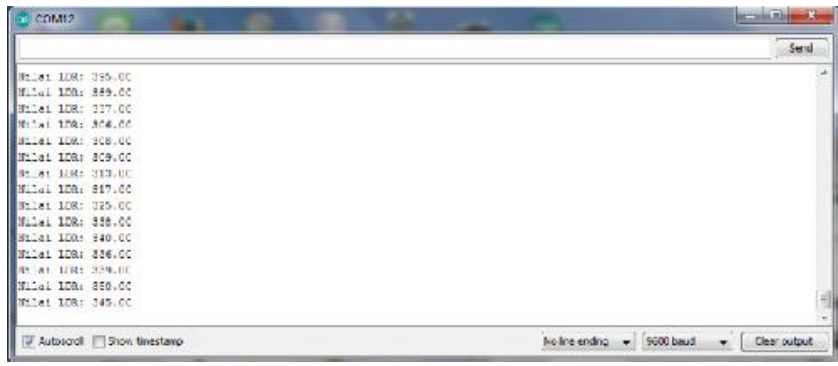

\section{Gambar 2.9 Serial Monitor Menampilkan Nilai LDR}

9. Catat nilai LDR yang didapat berdasarkan luas penampang cacat. Lalu buat grafik.

10.Cari persamaan dari grafik sehingga didapatkan bentuk persamaan $\mathrm{y}=\mathrm{m} \mathrm{x}+\mathrm{c}$.

Pemeriksaan kualitas kain dilakukan dengan memanfaatkan sensor cahaya pada mikrokontroler Arduino Uno dan menggunakan perangkat lunak Arduino IDE. Program IDE untuk bisa

\section{HASIL}

Pengujian dilakukan dengan pembacaan nilai minimal adalah 0,00 berarti kondisi gelap sama dengan mendapatkan output sesuai dengan yang diinginkan. Prinsip kerja dari penelitian ini adalah melewatkan lubang yang terdapat pada kain tepat di atas sensor LDR sehingga sesuai apa yang diperintahkan melalui program Arduino IDE akan didapat output nilai LDR pada serial monitor. Selanjutnya nilai LDR tersebut dibuat persamaan garis. Persamaan garis dimaksudkan sebagai pengkalibrasi nilai LDR terhadap luas penampang cacat.

pada saat sensor cahaya (LDR) tertutup kain. Tabel 3.1 menunjukkan perubahan nilai yang dibaca oleh sensor cahaya (LDR). Hasil pengamatan ini selanjutnya dibuat 
persamaan garis lurus sehingga sensor LDR dapat membaca diameter sebagai nilai LDR. Gambar 3.1 merupakan persamaan garis lurus dengan rata-rata

Tabel 0.1 Hasil Nilai Pendeteksi Cacat Kain Menggunakan Sensor Cahaya (LDR)

\begin{tabular}{|c|c|c|c|c|c|}
\hline & \multicolumn{5}{|c|}{ Luas $\mathbf{( m m}^{\mathbf{2}}$ ) } \\
\hline & $\mathbf{9}$ & $\mathbf{1 5}$ & $\mathbf{2 5}$ & $\mathbf{3 5}$ & $\mathbf{4 9}$ \\
\hline \multirow{3}{*}{$\begin{array}{c}\text { Nilai LDR } \\
\text { (byte) }\end{array}$} & 306 & 402 & 458 & 477 & 521 \\
\cline { 2 - 6 } & 308 & 404 & 458 & 479 & 522 \\
\cline { 2 - 6 } & 309 & 405 & 459 & 481 & 523 \\
\cline { 2 - 6 } & 313 & 406 & 460 & 484 & 524 \\
\cline { 2 - 6 } & 314 & 413 & 460 & 489 & 525 \\
\hline Rata-rata & $\mathbf{3 1 0}$ & $\mathbf{4 0 6}$ & $\mathbf{4 5 9}$ & $\mathbf{4 8 2}$ & $\mathbf{5 2 3}$ \\
\hline
\end{tabular}

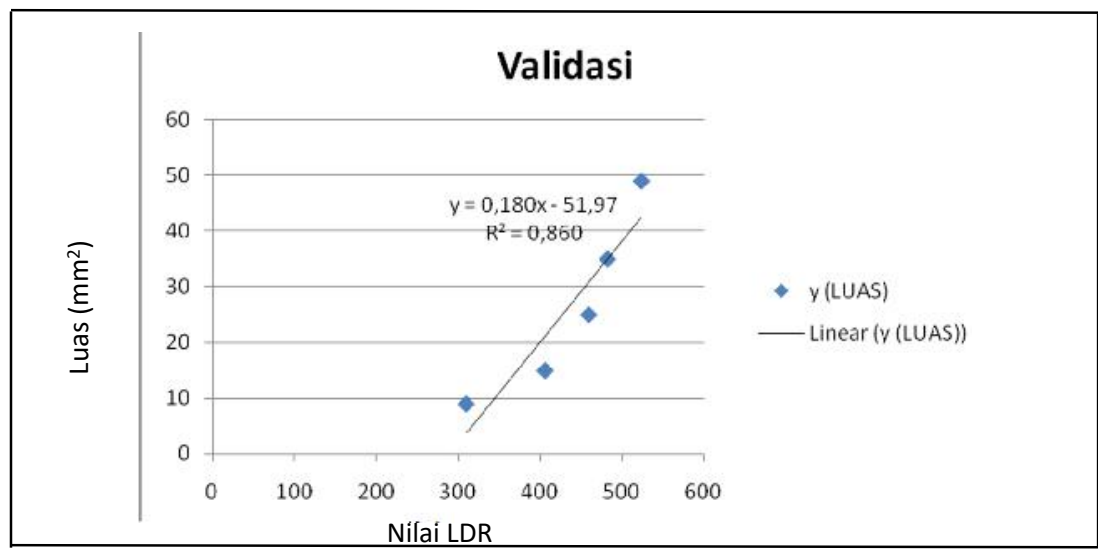

Gambar 0.1 Persamaan Garis Nilai LDR terhadap Luas

Hasil pembacaan nilai LDR pada Tabel 3.1 menunjukkan bahwa nilai LDR berbanding lurus dengan luas cacat yang diperiksa, artinya semakin besar ukuran luas cacat yang diperiksa semakin besar nilai LDR. Dari persamaan garis di atas maka didapatkan hasil $y=0,180 x-51,97$. Setelah mendapatkan persamaan garis lurus maka persamaan tersebut diinput ke dalam sketch Arduino Uno IDE sehingga nilai yang dibaca oleh sensor LDR untuk pemeriksaan cacat lubang merupakan luas penampang cacat pada kain $\left(\mathrm{mm}^{2}\right)$. Persamaan garis lurus tersebut berfungsi sebagai kalibrasi agar sensor LDR pada mikrokontroler Arduino Uno dapat nilai LDR sebagai $x$, sedangkan luas penampang cacat sebagai $y$. 
nilai2 atau ukuran luas penampang cacat pada serial monitor Arduino IDE. Setelah dilakukan pengujian dimana cacat lubang pada kain dilewatkan tepat diatas sensor LDR maka didapatkan hasil pengujian berupa ukuran luas yang didapat dari hasil pembacaan oleh sensor LDR. Selanjutnya ukuran luas tersebut dibandingkan akurasinya dengan ukuran sebenarnya yang sebelumnya telah diketahui.

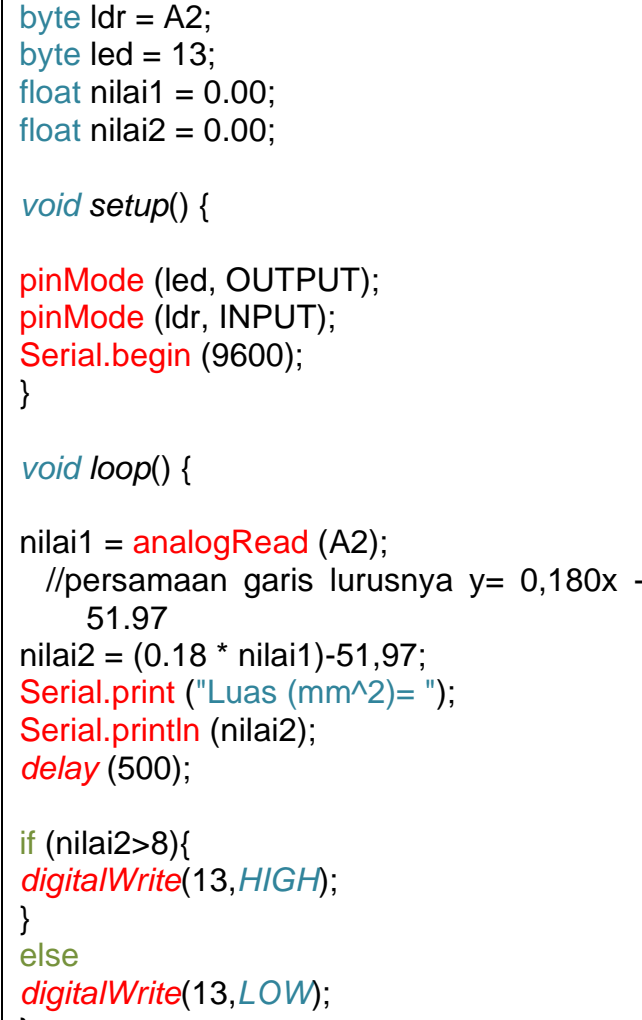

\section{Gambar 0.2 Sketch Baru untuk Menentukan Nilai Luas Penampang Cacat}

\section{PEMBAHASAN}

Penilaian cacat lubang kain berbasis sensor cahaya pada mikrokontroler Arduino Uno menghasilkan nilai luas dalam $\mathrm{mm}^{2}$. Terdapat selisih antara luas cacat yang dibaca oleh sensor LDR dengan luas sebenarnya yang dapat dilihat pada tabel 4.1. Selisih tersebut dapat ditimbulkan oleh berbagai macam faktor, selanjutnya persentase selisih ukuran luas terhadap luas sebenarnya akan dianggap sebagai akurasi alat. Perlu menjadi catatan pengujian awal untuk kalibrasi dengan output nilai intensitas cahaya dan pengujian akhir dengan output ukuran luas penampang cacat kain harus dilakukan dengan kondisi cahaya yang sama serta jarak antara cacat lubang dengan sensor yang sama. 
Tabel 4.1 Perbandingan Ukuran Luas Penampang Cacat Lubang Kain Berdasarkan Nilai LDR dengan Perhitungan Manual

\begin{tabular}{|c|c|c|c|c|c|}
\hline No & $\begin{array}{c}\text { Ukuran } \\
\text { penampang } \\
\text { cacat }(\mathrm{mm})\end{array}$ & $\begin{array}{c}\text { Luas } \\
\text { penampang } \\
\text { cacat }\left(\mathrm{mm}^{2}\right)\end{array}$ & $\begin{array}{l}\text { Luas } \\
\text { cacat dari } \\
\text { LDR } \\
\left(\mathrm{mm}^{2}\right)\end{array}$ & $\begin{array}{c}\text { Selisih } \\
\left(\mathrm{mm}^{2}\right)\end{array}$ & Akurasi (\%) \\
\hline 1. & $2 \times 2$ & 4,00 & 4,08 & 0,08 & 2,00 \\
\hline 2. & $2 \times 3$ & 6,00 & 6,24 & 0,24 & 4,00 \\
\hline 3. & $3 \times 4$ & 12,00 & 12,54 & 0,54 & 4,50 \\
\hline 4. & $4 \times 4$ & 16,00 & 16,44 & 0,44 & 2,75 \\
\hline 5. & $4 \times 5$ & 20,00 & 19,92 & $-0,08$ & 0,40 \\
\hline
\end{tabular}

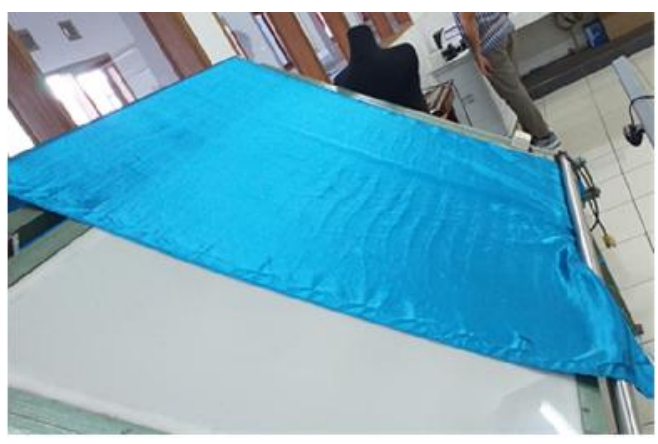

Gambar 4.1 Penggelaran kain di mesin inspeksi kain

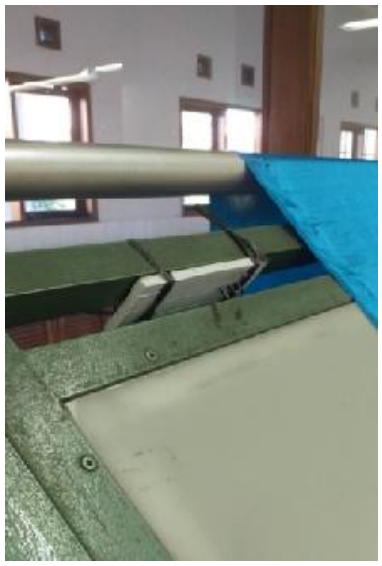

Gambar 4.2 Penempatan B readboard pada mesin inspeksi

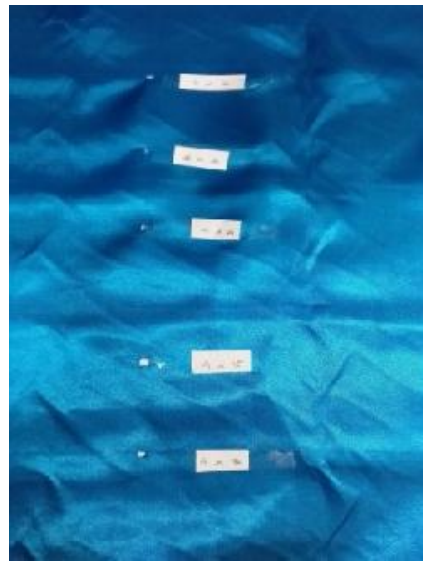

Gambar 4.3 Cacat Lubang kain dan ukuranya berdasarkan hasil pengukuran 


\section{KESIMPULAN DAN SARAN}

Berdasarkan hasil penelitian dan pembahasan mengenai studi pendeteksi cacat lubang kain berbasis sensor cahaya (LDR) pada mikrokontroler Arduino Uno, dapat diambil kesimpulan mengenai hasil analisis yang mengacu pada tujuan perancangan alat uji.

\subsection{Kesimpulan}

Dari hasil pengamatan dan pembahasan mengenai studi pendeteksi cacat lubang kain berbasis sensor cahaya pada Arduino Uno, maka dapat diambil kesimpulan:

1. Cacat lubang kain dapat dideteksi dengan sensor cahaya (LDR) dengan memanfaatkan kemampuan sensor untuk menangkap perubahan intensitas cahaya.

2. Arduino IDE sebagai software yang meneruskan perintah dapat diatur untuk dapat menampilkan secara langsung ukuran luas dari penampang cacat.

\subsection{Saran}

Berdasarkan pembahasan, maka ada beberapa hal yang dapat dilakukan untuk penelitian selanjutnya dengan mempertimbangkan hal-hal berikut ini:

1. Sensor hanya dapat menangkap perubahan intensitas cahaya yang langsung mengenai permukaan sensor.

2. Alat uji/prototype hanya bisa digunakan sebagai pendeteksi satu jenis cacat.

3. Penelitian prototype ini diharapkan dapat dikembangkan sebagai prototype yang cacat kainnya lebih bervariasi.

P rototype ini diharapkan dapat dikembangkan dengan menggunakan sensor jenis lain terhadap cacat kain yang lebih banyak jenisnya.

\section{DAFTAR PUSTAKA}

1. Ajjie, Septa. 2016. Buku Mudah Belajar Mikrokontroller dengan Arduino. http://academia.edu/11472322/Buku_Mudah_Belajar_Mikrokontroller_den gan_Arduino. Diakses 15 Mei 2019.

2. Albet dkk. 2014. Pembuatan Jendela Otomatis Menggunakan Sensor Cahaya. J urnal Media Inforama Volume 10 No. 1. 
3. Angga dkk. 2016. Saklar Otomatis Berbasis Light dependent resistor (LDR) pada Mikrokontroler Arduino Uno. Prosiding Seminar Nasional Fisika Volume V.

4. Ariani, Dorothea Wahu. 2004. Pengendalian Kualitas Statistik (Pendekatan Kuantitatif dalam Manajemen Kualitas). Yogyakarta: Andi Offset.

5. B. Gustomo. 2015. Pengenalan Arduino dan Pemrogramannya. Bandung: Informatika Bandung

6. Fitrihana Noor. 2013. Pengendalian Mutu Busana. Yogyakarta: Kompetensi Terapan Sinergi Pustaka

7. Hendrodyantopo, S. dkk. 2005. Pengendalian dan Jaminan Kualitas Pakaian J adi, Politeknik STTT Bandung.

8. J anah, Miftahul. 2017. Analisis Produk Cacat dan Produk Rusak (Studi di CV. Aneka Karya Glass Pabelan). Surakarta: Institut Agama Islam Negeri Surakarta.

9. Kadir, Abdul. 2013. Panduan Praktis Mempelajari Aplikasi Mikrokontroler dan Pemrogramannya Menggunakan Arduino. Yogyakarta : ANDI

10. Keyza Novianti, Chairisni Lubis, Tony. 2012. Perancangan Prototype Sistem Penerangan Otomatis Ruangan Berjendela Berdasarkan Intensitas Cahaya. Seminar Nasional Teknologi Informasi.

11. Nastiti, Heni. 2014. Analisis Pengendalian Kualitas Produk dengan Metode SQC. J urnal Manajemen Mutu Vol 6 No 1.

12.Roger S. Pressman. 2002. Rekayasa Perangkat Lunak. Yogyakarta : ANDI

13.Supriyono. 2001. Sistem Pengendalian Manajemen. Buku Dua Edisi Pertama. Yogyakarta: B PFE-UGM.

14. Tarwaka, Sholichul, Lilik Sudiajeng. 2004. Ergonomi Untuk Keselamatan, Kesehatan dan Produktivitas. Surakarta: UNIBA PRESS. 